\title{
The dependence of earthquake frequency magnitude relationship and strain energy release upon the focal depth in Hindu Kush region
}

\author{
J. C. Drakopotgos $(*)-$ H. N. Srivastaya $(* *)$
}

Received on .July $12 n d, 1972$

\begin{abstract}
Sumarr. - The dependence of earthquake frequency magnitude relationslip and the strain energy release upon the focal depth in Hindu Kush region las been studied based on I.S.C.G.S. data during the years 1963-1971 (March) and the results have been compared with those of the other investigators for European and Japanese region. It is seen that there is no positive evidence for the decrease of $b$ in Gutenberg-Richter's frequency magnitude relationship with the focal depth. The temporal variation of the elastic strain rebound also for these data does not show the same characteristic pattern as reported by Benioff for the deep focus earthquakes. Emphasis is given also to some facts relating to the seismotectonic regime of Hindu Kuslı area.
\end{abstract}

Riassunto. - In questa nota, gli Autori hanno studiato come la relazione frequenza-magnitudo dei terremoti e l'energia delle tensioni liberata nella regione dell'llindu Kush, dipendano dalla profondita dei terremoti stessi, basandosi sui dati dell'USCGS relativi agli anni 1963-197l (Mlarzo). I risultati sono stati confrontati con quelli ottenuti da altri ricercatori per la zona Europea e quella Giapponese. Non vi è alcuna prova che $b$, nella relazione frequenza-magnitudo di Gutenberg-Richter, decresca con la profondita del fuoco. Inoltre la variazione nel tempo della risposta ("rebound") delle tensioni elastiche per questi dati, non ha lo stesso modello caratteristico riportato da Benioff per i terremoti profondi. Vengono anche messi in evidenza alcuni fatti relativi all'andamento sismotettonico della regione dell'Hindu Kush.

(*) Seismological Laboratory, Athens, University, Greece.

(**) India Meteorological Department, Lodi Road, New Delhi-3, India. 
The magnitude frequency behaviour of different earthquake regions has been discussed by many authors ever since Gutenberg and Richter (10) established the formula:

$$
\text { or } \begin{aligned}
& \log _{10} N=a-b M \\
& N=10^{a} 10^{-b . M}
\end{aligned}
$$

where $N$ is the number of shocks of magnitude $M$ or greater and $a$ and $b$ are constants.

Many seismologists, e.g. Suzuki (21), have insisted that the values of the coefficient $b$ are empirically constant, within the limits of statistical variation for all earthquake regions ever investigated. Also Isacks and Oliver (") suggested that a large part of the variation of the $b$ value can be attributed to statistical fluctuation or observational uncertainties. It has been established by Miyamura (15), that the magnitude frequency behaviour of each earthquake region bears a close relation to the tectonic stage of development of that region. Generally speaking, earthquakes are considered to be manifestations of tectonic movements in each region. Examining many seismicity investigations it can readily be concluded, that the tectonically younger stage is represented by the larger value of $b$ and the older stage by the smaller value of $b$.

The dependence of the $b$ value in the Gutenberg-Richter's frequency magnitude relationship upon the focal depths of earthquakes has attracted the attention of several workers. Similarly, the pattern of the seismic strain energy release associated with the earthquakes occurring at different focal depths has been the subject of interest.

Gutenberg and Richter ( $\left.{ }^{10}\right)$ obtained the magnitude frequencies of shallow, intermediate and deep earthquakes for the whole world and gave the following values of $b$;

$$
\begin{array}{ll}
\text { Shallow shocks } & b=0.90 \pm 0.02 \\
\text { Intermediate shocks } & b=1.2 \pm 0.2 \\
\text { Deep shocks } & b=1.2 \pm 0.2
\end{array}
$$

For the intermediate shocks of Hindu Kush region, however the authors reported a rather low value of 0.6 and suggesterl smaller breaking strength and/or greater plasticity at depth. 
Asara (1) found that $b=0.6$ for deep focus earthquakes, while $b=0.9$ for shallow earthquakes which is in agreement with the results in Hindu Kush region. Galanopoulos $\left(^{9}\right)$ reported that the values of $b$ for shallow and intermerliate earthquakes in Greece are of the order of 0.82 and 0.42 respectively. Katsumata ( $\left.{ }^{13}\right)$ did not find any significant difference between $b$ values for shallow, intermediate and deep shocks both for the Japanese region and the whole world.

Recently, Chouhan and Srivastava (j) have studied the global variation of $b$ in Gutenberg Richter's relationship with depth and reported a value of $b$ around $0.6 \overline{\mathrm{up}}$ to the focal depth of $300 \mathrm{~km}$. It thus appears, that the problem requires further sturly using reliable data. The main object of the present paper is therefore, to investigate the dependence of $b$ and strain energy release upon focal depth.

\section{$2 .-$ DATA}

The epicentral coordinates of the earthquakes in Hindu-Kush region have been taken from the monthly listings prepared by U.S.C.G.S. for the years 1963-1971 (up to March only). In order to check the general validity of the results, the data for the period 190 ; to 1971 as publisherl in the seismicity of the Earth (10) were also subjected to similar analysis for the sake of comparison. It is obvious, that such study brings out the affect of using two magnitude scales. In order to examine this point more closely, the borly wave magnitude $M_{B}$, Wood Anderson magnitude $H_{L}$ as determined from the re-

Table I - Difrerence in MaGintudes: $M_{B}, M_{L}$ AND $M_{C G S}$

\begin{tabular}{|c|c|c|c|c|c|c|c|}
\hline \multirow{2}{*}{ No. } & \multirow[t]{2}{*}{ 1)ate } & \multirow{2}{*}{$\begin{array}{c}\text { Epicentre } \\
\text { NGS } \\
N \quad \mathrm{E}\end{array}$} & \multirow{2}{*}{$\begin{array}{c}\text { Focal depth } \\
\text { CGS } \\
\text { km }\end{array}$} & \multirow{2}{*}{$\begin{array}{c}\text { Origin Time } \\
\text { CGS } \\
\text { h } \mathrm{m}:\end{array}$} & $1 / I_{B}$ & $y_{L}$ & \multirow[t]{2}{*}{ II CGS } \\
\hline & & & & & \multicolumn{2}{|c|}{ At N. Delhi } & \\
\hline 1. & 26.1 .70 & $36.5^{\circ}, 70.4^{\circ}$ & 224 & $16: 38: 31.7$ & 5.8 & 6.7 & 4.7 \\
\hline 2. & 15.3 .70 & $36.4^{\circ}, 70.9^{\circ}$ & 220 & $18: 34: 08.3$ & 5.0 & 6.3 & 4.9 \\
\hline 3. & 11.6 .70 & $36.5^{\circ}, 71.1^{\circ}$ & 184 & $17: 40: 50.4$ & 一 & 6.8 & 5.2 \\
\hline 4. & 21.8 .70 & $36.1^{\circ}, 68.5^{\circ}$ & 98 & $15: 25: 56.8$ & 5.6 & 6.0 & 5.2 \\
\hline$\tilde{5}$. & 14.9 .70 & $36.4^{\circ}, 70.1^{\circ}$ & 219 & $16: 11: 15.6$ & 5.8 & 6.5 & 5.1 \\
\hline 6. & 11.1 .71 & $36.9^{\circ}, 71.6^{\circ}$ & 163 & $20: 21: 34.3$ & 5.5 & 6.4 & 4.6 \\
\hline
\end{tabular}


cords at New Delhi and Mcos have been given in Table 1, for some earthquakes in Hinclu Kush region. The differences between, appear to be irregular for any uniform correction to be applied and thus, the retermination of $b$ may yield different values rlepending upon the rhoice of the magnitude soale.

3. - Sonf aspects abott THE Seisuotectoxic Regine of the dred

Most of the large Hindu Fush earthquakes with their depth of foci lying between $21010250 \mathrm{~km}$ had their origin in the same area lying between the parallels of latiturle $36^{\circ} \mathrm{N}$ and $37^{\circ} \mathrm{N}$ and longiturle $70^{\circ} \mathrm{E}$ and $71^{\circ} \mathrm{E}$. This is the area which romes under the Pamir massif with its special geological feature and an area where conspicuous negative gravity anomalies prevail.

The Himalaya's complex, which inclurles most of the Mlpirle compressive belt from Iran to Burma is the only orogenic area without recent volanism. This region is similar to other areas of negative gravity in having great thicknesses of sedimentary rocks and no volcanism. Otherwise, it is more similar to the other compressive regions which are positive gravity anomalies (14).

A structural majp of Findu Kush area is given (4) in fig. 1 showing major faults.

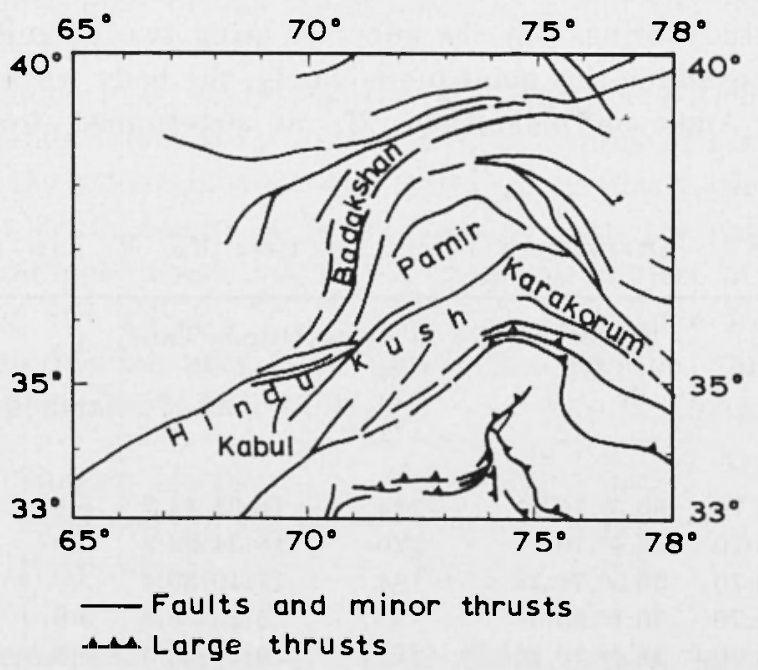

Fig. 1 - A structural map of Hindu Kush (after Chouhan), showing major faults. 
From studies of Santo (19), the epicenters of the events shallower than $100 \mathrm{~km}$ in and around Hindu Kush, are distributed near the southern foots and parallel to the trends of a few mountain chains, while those deeper than $100 \mathrm{~km}$ concentrate into a restricted area, in the Hindu Kush region.

In the western most part Hindu Kush, two continental plates seems to have underthrusted into the upper mantle from both sides, which form a V shaped lithospheric space quite locally in the Hindu Kush and general upper mantle events in that space. In the central part, interaction of the two continents acts only in the crust widely beyond the Tibet plateau. The previously reported fact that large deep focus earthquakes always occur more or less at the same depth which is of the order of $220 \mathrm{~km}$ and having the same epicenter $\left(36.5^{\circ} \mathrm{N}\right.$ $70.5^{\circ} \mathrm{E}$ ), would suggest the existence of a common cause for their origin. In fig. 2 it is seen the depth distribution of earthquakes along $\mathrm{N}-\mathrm{S}$ profile in and very near to $71^{\circ} \mathrm{N}$. In this figure, the horizontal seale is the same with the vertical and topography along the $71^{\circ} \mathrm{N}$ meridian is shown for comparison. The data are from USCGS cards for the years 1963-1971. The observation of Santo (19) about the existence of a $\mathbf{V}$ shaped lithospheric space in the region it is obvious from the fig. 2 .

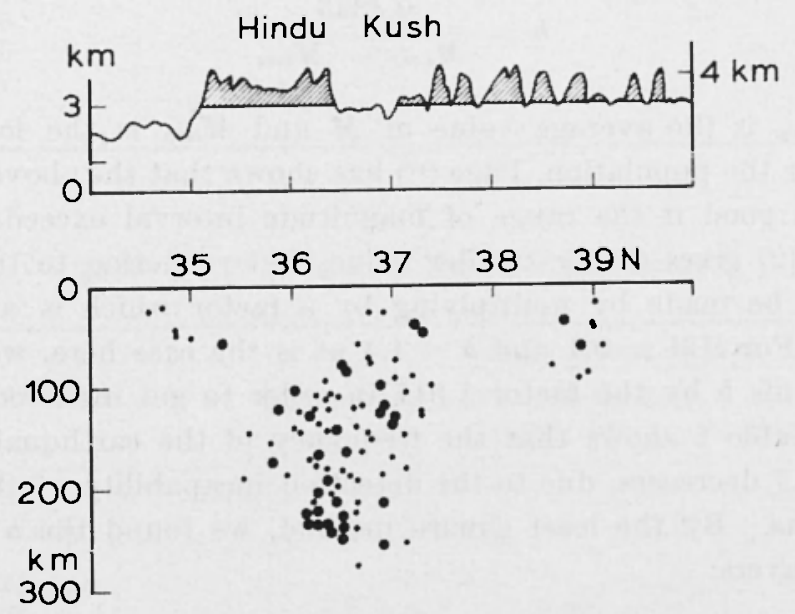

Fig. 2 - Depth distribution of the earthquakes in Hindu Kush along the profile N-S. Topography along the $71^{\circ}$ meridian is shown for comparison. Horizontal and vertical scale is the same. 
Ritsema ( $\left.{ }^{18}\right)$ studied the mechanism in the foci of 21 Hindu Kush events in the period 1917-1941 with the depths of around $220 \mathrm{~km}$ centering of $36.5^{\circ} \mathrm{N}, 70.5^{\circ} \mathrm{E}$ and obtained the stress condition of compressive force acting in the NW-SE trending Hindu mountain system. From the seismograms of some earthquakes in different periods originating at the similar spots, some other investigators also obtained similar results regarding the stresses effective in the foci of the Hindu Kush earthquakes.

\section{4. - MFTHOD OF AXIITSIS}

\subsection{THE valus: of $b$}

It is well known that the frequency magnitude relationship is expressed by equation [1].

The slope $b$ can be computed for different focal depths in Hindu Kush region. Accordingly, five intervals of depths ranging at every $50 \mathrm{~km}$ interval from the surface of the Earth could be chosen and the frequency, $N$ of earthquakes in different depth ranges for different magnitudes is given in Table 2. Utsu $\left({ }^{23}\right)$ has suggested that the value of $b$ can be estimated from the relation

$$
b=\frac{0.4343}{M_{\text {arer }}-M_{m i n}}
$$

where $M_{a v e r}$ is the average value of $M$ and $M_{m i n}$ is the lowest magnitude for the population. Page (17) has shown that the above relationship holds good if the range of magnitude interval exceeds 2 units. Equation [2] gives rather smaller values but reduction to the correct value can be made by multiplying by a factor which is a function of $b \Delta M$. For $A M=0.1$ and $b=1.4$ as is the case here, we have to multiply this $b$ by the factor 1.017 in order to get more correct value $\left.{ }^{24}\right)$. Table 2 shows that the frequency of the earthquakes below $M_{c c s}=4.7$ decreases, due to the detection incapability of the recording stations. By the least square method, we found the $b$ for three different layers:

1) depth from surface to $100 \mathrm{~km}$

2) depth range $100-200 \mathrm{~km}$

3) depth $>200 \mathrm{~km}$ 
THE DEPENDENCE OF EARTIROAKE FREQUENCY MAGNITUDE ETC. 599

Table 2 - Magsitude Frequexcy Relationship ix HiNdu Kusi Region (1963-1971, March)

\begin{tabular}{|c|c|c|c|c|c|}
\hline \multirow[b]{2}{*}{ Magnitude $O G S$} & \multicolumn{5}{|c|}{ Frequency of earthquakes } \\
\hline & $\begin{array}{l}0.50 \\
k m\end{array}$ & $\begin{array}{c}51 \cdot 100 \\
\mathrm{~km}\end{array}$ & $\begin{array}{c}101-150 \\
\mathrm{~km}\end{array}$ & $\begin{array}{c}151-200 \\
\mathrm{~km}\end{array}$ & $\geqslant \underset{\mathrm{km}}{200}$ \\
\hline $\begin{array}{l}4.1 \\
4.2 \\
4.3 \\
4.4 \\
4.5 \\
4.6 \\
4.7 \\
4.8 \\
4.9 \\
5.0 \\
5.1 \\
5.2 \\
5.3 \\
5.4 \\
5.5 \\
5.6 \\
5.7 \\
5.8 \\
5.9 \\
6.0 \\
6.1 \\
6.2 \\
6.3 \\
6.4 \\
6.5 \\
6.6 \\
6.7\end{array}$ & $\begin{array}{l}1 \\
1 \\
1 \\
-1 \\
4 \\
4 \\
8 \\
2 \\
3 \\
5 \\
1 \\
3 \\
1 \\
1 \\
- \\
- \\
- \\
- \\
- \\
- \\
-\end{array}$ & $\begin{array}{l}- \\
- \\
- \\
-1 \\
2 \\
1 \\
4 \\
1 \\
2 \\
3 \\
4 \\
2 \\
- \\
- \\
- \\
1 \\
- \\
- \\
- \\
- \\
- \\
-\end{array}$ & $\begin{array}{l}- \\
1 \\
2 \\
2 \\
-7 \\
3 \\
7 \\
8 \\
5 \\
2 \\
5 \\
- \\
1 \\
1 \\
- \\
- \\
- \\
- \\
- \\
-\end{array}$ & $\begin{array}{c}- \\
1 \\
2 \\
1 \\
6 \\
2 \\
2 \\
1 \\
2 \\
1 \\
1 \\
2 \\
1 \\
1 \\
- \\
- \\
- \\
- \\
- \\
- \\
--\end{array}$ & $\begin{array}{r}1 \\
1 \\
1 \\
3 \\
5 \\
6 \\
9 \\
7 \\
6 \\
3 \\
1 \\
1 \\
1 \\
-1 \\
-1 \\
1 \\
- \\
1 \\
-\end{array}$ \\
\hline
\end{tabular}

Table 3 - $b$ values in Hindu Kusi region

\begin{tabular}{|c|c|c|c|}
\hline \multirow[b]{2}{*}{ Authors } & \multicolumn{3}{|c|}{ Depth Range in $\mathrm{km}$} \\
\hline & $\underset{\mathrm{k} \text { Surface to }}{ } 100$ & $\begin{array}{c}100 \text { to } 200 \\
\mathrm{~km}\end{array}$ & $\underset{\text { Earthquakes }}{\text { All }}$ \\
\hline Present study & $1.5 \pm 0.2$ & $1.4 \pm 0.2$ & $1.43 \pm 0.15$ \\
\hline $\begin{array}{l}\text { Gutenberg and } \\
\text { Richter }\left({ }^{(0)}\right) . . . .\end{array}$ & $1.2 \pm 0.2$ & 0.60 & - \\
\hline $\begin{array}{l}\text { Chouhan and } \\
\text { Srivastava }\left(^{5}\right) . . . .\end{array}$ & 一 & 0.68 & 一 \\
\hline
\end{tabular}




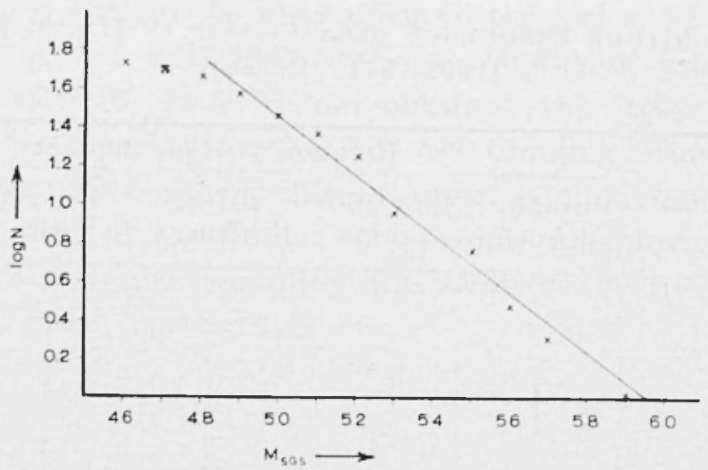

Fig. $3-\log N$ versus $M_{C G S}$ for focal depth $0<h<100 \mathrm{~km}$.



Fig. $4-\log N$ versus $M_{C G S}$ for $h>200 \mathrm{~km}$ and for $100 \mathrm{~km}<h<200 \mathrm{~km}$.

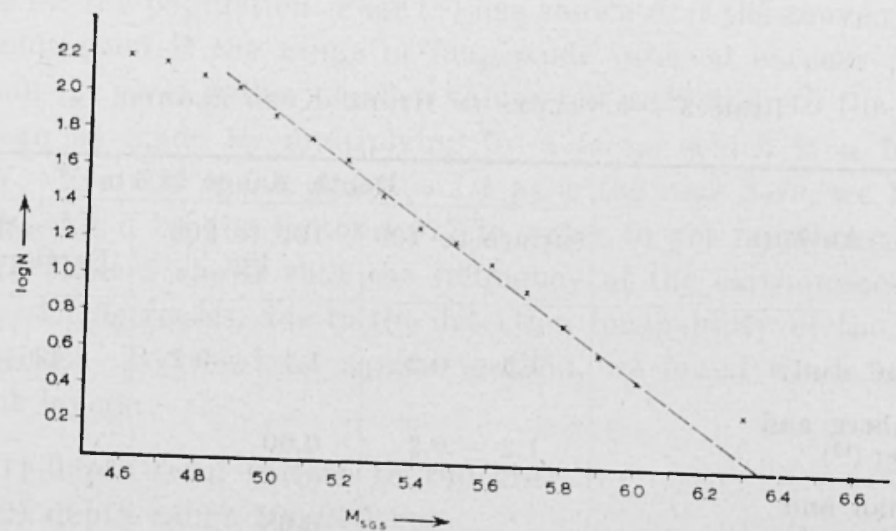

Fig. $5-\log N$ versus $M_{C G S}$ for all earthquakes. 
Also we calculated the $b$ value for all earthquakes, independently of the depth (see fig. $3,4,5$ ). It may be noticed that the population sample was not so sufficient and from this fact, the standard deviation in all calculated $b$ was rather large. Also we calculated $b$ for depth $h_{h}<100 \mathrm{~km}$ and for all the earthquakes independently of depth using the equation [2]. The corresponding values between the two methods had not substantial differences. It may be mentioned, that the value of $b$ could not be determined for the other depth ranges, as the range of magnitude interval was less than two units and thus, equation [2] could not be used (17). The values of $b$ by the least square method are given in Table 3 . Also in this Table, $b$ values from Hindu Kush area given by other authors are presented.

\subsection{STRAIN ENERGY RELEASE}

Benioff $\left({ }^{2}\right)$ has shown that the potential energy $J_{p}$ of a volume of rock $W$ possessing a coefficient of shear $\mu$, strained an average amount $S$ immediately before an earthquake is given by

$$
J_{p}=0.5 \mu W S^{2}
$$

and the energy of released seismic waves is

$$
J=0.5 f \mu W S^{2}
$$

where $f$ is the fraction of energy released as seismic waves.

In order to calculate the strain energy release, $J$, from U.S.C.G.S., we tentatively applied the relationship between $J$ and $M_{B}$, given by Bath:

$$
\log J=5.78+2.48 M_{B}
$$

It may be mentioned here that unified and U.C.S.G.S. magnitudes are not equal. While the latter is strictly to be determined from the vertical component seismograms of the short period instruments, the former is defined as the weighted mean of $M_{p z}, M_{p p z}, M_{s}$ etc.

The elastic strain rebound increment $J^{1 / 2}$ is proportional to the square root of the energy released $J$. Fig. 6 shows the temporal variation of the cumulative elastic strain $\Sigma J^{1 / 2}$. 


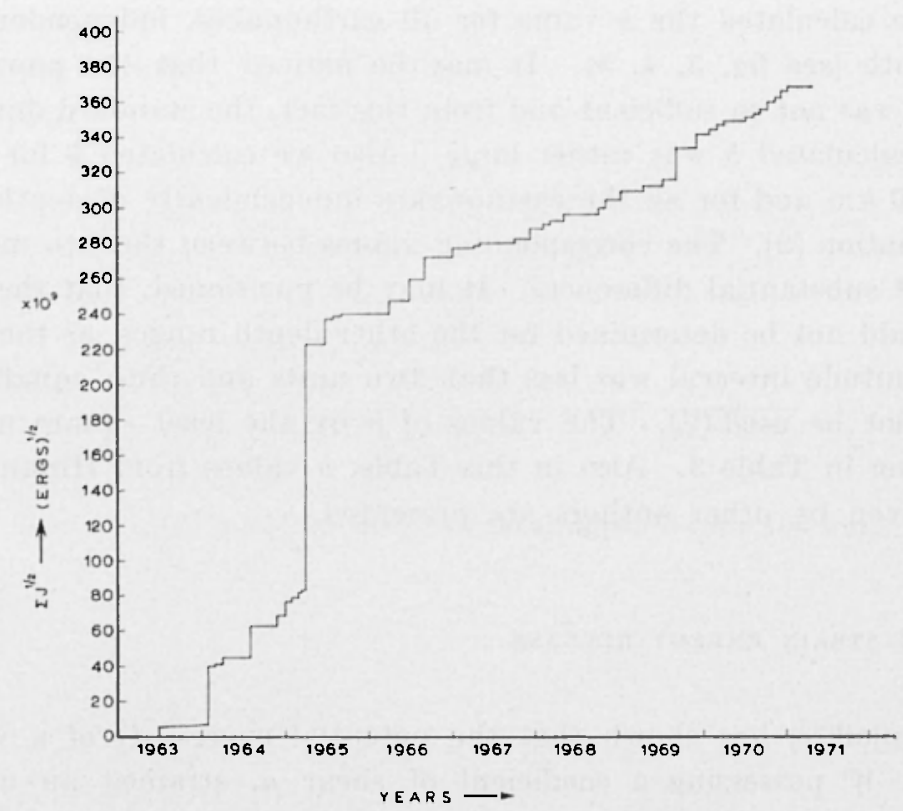

Fig. 6 - Temporal variation of elastic strain rebound.

\section{5. - REsults AND DIScUSSION}

It may be seen from Table 3 , that the value of $b$ remains almost constant for all the focal depth intervals considered for Hindu Kush region. It is interesting to find that the value of $b$ is almost twice that obtained by using surface wave magnitude, given from Gutenberg and Richter. The constancy of $b$ with depth up to $300 \mathrm{~km}$ is in agreement with the results of Chouhan and Srivastava (5) on global basis, but their absolute values differ widely. The difference in the $b$ values may be reflecting the differences in the two magnitude scales as well as the differences in the number of samples. Evernden ( ${ }^{8}$ ) observed that $b$ values from $M_{b}$ data were consistently larger than $M_{L}-b$ values for world-wide earthquakes but only for those with $M>5$.

Since, however the adoption of U.S.C.G.S. magnitudes is subject to lesser errors and on the contrary, $M$ as given in the seismicity of the Earth was determined with less sensitive instruments, the reliability of the results presented in this paper becomes quite clear. The results in Hindu Kush region differ significantly from that 
of Karnik (12), who found evidence for a decrease of $b$ with the focal depth in Europe and gave the relationship

$$
b=1.35-0.42 \log h .
$$

According to equation [6], the value of $b$ at a depth of $100 \mathrm{~km}$, becomes 0.51 which is too small to be accounted from the recent U.S.C.G.S. data.

The rather large value of $b$ obtained here compares with that found for earthquake swarms which are associated with a high degree of heterogeneity. A recent study by Drakopoulos et al. ( ${ }^{7}$ ) shows however that the value of $b$ in Matsushiro microearthquake swarms in Japan may vary from 0.9 to 1.2 .

According to Miyamura $\left({ }^{15}\right)$, high values of $b(1.0-1.8)$ are correlated with the Circum-Pacific and Alpine orogenic zones. Tsuboi ${ }^{(22)}$ found for different regions in the world $b$ values between 0.5 and 1.3. It is possible that these values of $b$ may also change significantly on the basis of recent U.S.C.G.S. data.

In order to compare $b$ values there it must be identity in the preparation of data, in the class interval, observation period, method of calculation and arrangement of data in ordinary or cumulative frequency. The deviations from these principles may cause artificial differences.

Srivastava and Kamble (20) have shown that the value of $b$ from aftershock data fails to reflect the seismotectonics of different regions in India. From a detailed study of the aftershocks of 1966 ParkfieldCalifornia earthquake, it was found that the values of $b$ differ significantly, being 0.94 for the shallow group and 0.73 for the deep group.

It has been found by many seismologists $(6,16)$ that the values of $b$ are larger for aftershocks than for foreshocks. The constants $b_{f}$ and $b_{a}$ of the fore - and aftershock sequences of the same main shock are connected by the relation $\left({ }^{6}\right)$ :

$$
b_{f}=(0.11 \pm 0.13)+(0.65 \pm 0.11) b_{a} .
$$

Mogi (16) showed experimentally that when foreshocks and aftershocks come from the same volume, the value of $b$ is smaller for foreshocks than for aftershocks, because the main shock causes new cracks and thus, the number of irregular points increases. Karnik (12) found that the value of $b$ is larger in aftershocks than in normal earthquakes.

Mogi (16) has shown experimentally, that the value of $b$ depends upon the homogeneity of the material in the seismic region and on the 
distribution of the applied stress. Since the homogeneity of the Earth, apparently increases with the focal depth, the value of $b$ may appear to decrease with $h$. In Hindu Kush region however, the earthquakes originating from upper mantle have been attributed to the compressive force, due to the interaction of $A$ sian and Indian continental blocks. The large stresses, due to the underthrusting of the two plates into the upper mantle, may be responsible for rather large value of $b$ in the region.

The temporal variation of $\Sigma . J^{1 / 2}$ in Hindu Kush region for $M_{c G S}>4.9$ is given in fig. 6. It may be seen, that the elastic strain rebound curve in the Hindu Kush region does not resemble the usual pattern as found for deep focus earthquakes (3). While this result is attributed to the short span of time for which U.S.C.G.S. data are available, the affect of different magnitude scales on strain energy release curve, cannot be ruled out completely. Chouhan (4) by using data (19071968) for Hindu Kush earthquakes with $M>6.75$, has found a curve for $\Sigma \cdot J^{1 / 2}=f(t)$ which exhibits a systematic release of strain in cyclic pattern as was shown by Beniofi for deep earthquakes on a global basis.

An attempt, was also made to study the energy distribution of the earthquakes in Hindu Kush versus depth, for $M>4.9$ (1963-1971). The result was that the maximum of the energy is released by a focal depth range of $190-230 \mathrm{~km}$. Another peak for the energy corresponds to a focal depth of $120-130 \mathrm{~km}$. These results are in general agreement with the fig. 2, where most of the large foci lie around these depths. The small amount of the release energy in the depth range from $150 \sim$ $190 \mathrm{~km}$ in Hindu Kush has been observed by Santo (19) and it was confirmed by the present study using more recent data. Santo ${ }^{\left({ }^{19}\right)}$ considers, that physical property of the low-velocity layer, will loses generally the capacity to store the strain energy. So by the detection of the depth ranges of less seismic activity in the upper mantle, we may get information about the regional variation of the depth, as well as the thickness of the low velocity layer, beneath various tectonic regions.

\section{5. - Conclusions}

The above study has shown, that there is no evidence for the decrease of $b$ in Gutenberg-Richter's frequency magnitule relation- 
ship with the focal depth in Hindu Kush region. The large value of $b$ has been attributed to the large stresses, due to the underthrusting of the two plates into the upper mantle. The temporal variation of the elastic strain rebound does not show the usual characteristic pattern as reported by Benioff ( ${ }^{3}$ ) for deep focus earthquakes. The maximum of the energy in Hindu Kush is released by a focal depth range of $190-230 \mathrm{~km}$, while a secondary maximum it comes from a focal depth of $120-130 \mathrm{~km}$.

Thanks are due to Miss M. Iouka for her kind help in the preparation of the manuscript.

\section{REFERENCES}

(1) AsADA T., 1957. - A sensus of earthquakes with particular rejerence to Japanese shocks. "Kag. Iwah. Shoten", 27, 444-450.

(2) BeniofF H., 1949. - Seismic evidence for the fault origin of ocean deep. "Bull. Geol. Soc. Am.", 60, 1837-1848.

(3) BeviofF II., 1951. - Global strain accumulation and released by great earthquakes. "Bull. Geol. Soc. Am.", 62, 331-349.

(4) CrounaN R., 1969. - Seismotectonies of Hindu Kush. "Pure and Applied Geoph.", 108-118.

(5) Chouilax R. and SRIvastava V., 1970. - Global variation of $b$ in the Gutenberg Richter's relation $\log N=a-b M$ with depth. "Pure and Applied Geoph.", 124-132.

$\left.{ }^{6}\right)$ Drakopoulos J., 1968. - Characteristic parameters of Fore - and Aftershock sequences in the region of Greece. Dissertation for cloctor clegree, $\Lambda$ thens Univ., Greece.

(7) Drakopoulos .I., Srivastava II. and Terashima T., 1970. - Seismicity of Matsushiro miero earthquale swarm. "Ann. di Geof.", XXIII, 2, $177-190$.

(8) EvERNDEN J., 1970. - Study of regional seismicity and associated problems. "Bull. Seism. Soc. Am.", 60, 393.

$\left({ }^{9}\right)$ Gatanopoulos A., 1965. - Evidence for the seat of the strain-producing forces. "Ann. di Geof.", XVIII, 4, 399-409.

(10) Gutenberg B, and Richter C., 1954. - Seismicity of the Earth and associated phenomena. "Princeton University Press".

(11) IsACKS B. and OLIVER J., 1954. - Seismic waves with frequencies 1 to 100 eycles per second recorded in a deep mine in Northern New Jersey. "Bull. Seism. Soc. Am.", 54, 1941-1979. 
(12) Kansı V., 1964. - Magnilude - Frequency relalion and Seismic Aclivily in different regions of the European area. "Bull. Intern. Inst, of Seism. and Earth. Engin.", 1, 9-32.

(13) Katsumata M., 1967h. -- Seismic aetivilies versus deplh. "Zisin", 20. $75-84$.

(14) Kavus W., 1971. - The global variations of the Earth's gravity. "Natur. wissenschaften", 58, 116-120.

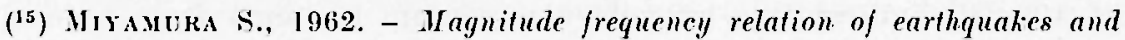
its bearing on geotectonics. "Proc. Jap. Acad.", 38, 27-30.

(18) MoGi K., 1962. - Study of elastie shocks caused by the fracture of heterogeneous materials and its relations of earthquate phenomena. "Bull. Earth. Res. Inst.", 40, 124-174.

(17) PAciv R., 1968. - Aftershocks and Microaftershocks of the great Alasha earlhquake of 1964. "Bull. Seism. Soc. Am.", 58, 1131-1168.

(18) Ritsema R., 1955. - The fault plane technique and the mechanism in the focus of Hindu Kush earthquakes. "Ind. J. Met. Geoph.", 6, 1-10.

(1i) SAxтo T., 1969. - Regional study on the chacteristic seismicity of IIindu Kush region. "Bull. Warth. Res. Inst.", 47, $1035-1048$.

$\left(^{(20}\right)$ SRIVAstava H. and Kambi.e V., 1972. - Aftershock sequences in and near India. "Ind. Journ. Met. and Geoph." (in Press).

$\left(^{21}\right)$ SUzukI \%, 1959. - A statistical study on the occurrence of small earth. quakes. "Sci. Rep. Tohoku liniv., Ser. V. Geoph.", 10-54.

(\#) Tsubor C., 1958. - Seismic activities in and near Japan. "Contribution in Geophysies", Pergamon Press, Jondon.

$(-3)$ Utsu T., 1965. - A method for delermining the value of $b$ in a formula $\log N=a-b$. If showing the magnitude frequency relation for earthquakes. "Geoph. Bull. Hokkaido Univ.", 13, 99-104.

(24) UTsu T., 1966. - A statistical significance test of the difference in b value between two earthquake groups. "Jour. of the Physies of the Earth", 14, $37-40$. 